\title{
True Stress-True Strain Relations with Very Low Strain Rates at Room Temperature for an Austenitic 25Cr-19Ni Steel
}

\author{
N. TSUCHIDA, E. BABA, ${ }^{1)}$ O. UMEZAWA, ${ }^{2)}$ K. NAGAl' ${ }^{3)}$ and Y. TOMOTA ${ }^{4)}$ \\ Domestic Research Fellow, Japan Society for the Promotion of Science, Sengen, Tsukuba, Ibaraki 305-0047 Japan. \\ 1) Materials Information Technology Station, National Institute for Materials Science, Nakameguro, Meguro-ku, Tokyo 153- \\ 0061 Japan. $\quad 2$ ) Graduate School of Engineering, Yokohama National University, Tokiwadai, Hodogaya, Yokohama, \\ Kanagawa 240-8501 Japan. $\quad$ 3) Steel Research Center, National Institute for Materials Science, Sengen, Tsukuba, Ibaraki \\ 305-0047 Japan. $\quad$ 4) Faculty of Engineering, Ibaraki University, Nakanarusawa, Hitachi, Ibaraki 316-8511 Japan.
}

(Received on June 13, 2003; accepted in final form on August 30, 2003)

\begin{abstract}
True stress $(\sigma)$-true strain $(\varepsilon)$ relations at very low strain rates at room temperature are compared in creep and tensile tests to investigate the effect of deformation history on the $\sigma-\varepsilon$ relation and the applicability of the Kocks-Mecking (KM) model for the austenitic 25Cr-19Ni steel. Experimental results obtained by the creep and the tensile tests indicate that the $\sigma-\varepsilon$ relation is not influenced by prior deformation history at true strains below 0.2 . The $\sigma-\varepsilon$ curves at very low strain rates between $10^{-8}$ and $10^{-10} \mathrm{~s}^{-1}$ obtained by the creep test are in accordance with those calculated by the KM model as well as that measured by the crosshead-arresting test. The KM model is concluded to be applicable to the $\sigma-\varepsilon$ relations at very low strain rates obtained by various deformations.
\end{abstract}

KEY WORDS: austenitic stainless steel; creep; strain rate; modeling.

\section{Introduction}

We have studied the description of true stress $(\sigma)$-true strain $(\varepsilon)$ relation below room temperature by applying the Kocks-Mecking (KM) model ${ }^{1)}$ for various alloys like the alpha $\mathrm{Ti}$ alloy, ${ }^{2,3}$ the austenitic $25 \mathrm{Cr}-19 \mathrm{Ni}$ steel (JISSUS310S), ${ }^{4)}$ and ferritic steels. ${ }^{5,6)}$ We conducted tensile tests with strain rates from $10^{-9}$ to $10^{-2} \mathrm{~s}^{-1}$ at temperatures between 77 and $296 \mathrm{~K}$. For the alpha Ti alloy ${ }^{2}$ and the austenitic $25 \mathrm{Cr}-19 \mathrm{Ni}$ steel, ${ }^{4}$ ) the $\sigma-\varepsilon$ relations at very low strain rates were obtained by a crosshead-arresting test in which the changes in load and displacement were recorded after the crosshead was arrested at several displacements. After a sufficiently long time, the changes either in load or in displacement became non-detectable. ${ }^{3)}$ Measured $\sigma$ and $\varepsilon$ relations in the crosshead-arresting test agreed well with the calculated $\sigma-\varepsilon$ relations at the strain rate of $10^{-9} \mathrm{~s}^{-1}$ by using the KM model for the both alloys., ${ }^{2,4)}$ Judging from those results, the strain rate of $10^{-9} \mathrm{~s}^{-1}$ is considered to be the technically detectable minimum rate with high accuracy for the tensile tests. However, it takes too long time to determine the $\sigma-\varepsilon$ curve with a strain rate of $10^{-9} \mathrm{~s}^{-1}$ by the conventional tensile test. Hence, we have proposed that the crosshead-arresting test ${ }^{2}$ is very effective for obtaining the $\sigma-\varepsilon$ relation efficiently at $10^{-9} \mathrm{~s}^{-1}$. Among the materials investigated above, the $25 \mathrm{Cr}-19 \mathrm{Ni}$ steel shows a characteristic behavior; the microstructure evolution with deformation is hardly dependent on temperature and strain rate when the tensile strain is less than 0.2 . $^{4)}$ Hence, the mechanical threshold stress, indicating the microstructural pa- rameter in the $\mathrm{KM}$ model, is independent of temperature and strain rate in the investigated range. Since the $25 \mathrm{Cr}-$ $19 \mathrm{Ni}$ steel shows a comparatively low stacking fault energy of $50 \mathrm{~J} / \mathrm{m}^{2},{ }^{7,8)}$ dynamic recovery hardly occurs and twinning is not introduced during deformation at strains less than 0.2 . This suggests that the flow stress for the $25 \mathrm{Cr}-19 \mathrm{Ni}$ steel is not affected by straining history at strains below 0.2 . $^{\text {) }}$

Low temperature creep under constant load is a kind of low strain rate tensile test. In this study, we have tried to obtain the $\sigma-\varepsilon$ relations at low strain rates by conducting the creep test under the constant applied load at room temperature for the austenitic $25 \mathrm{Cr}-19 \mathrm{Ni}$ steel. First, the independence of the $\sigma-\varepsilon$ relation at very low strain rates on the deformation history is confirmed with respect to the room temperature creep. Then the $\sigma-\varepsilon$ relations obtained by the creep test are compared with those calculated by the KM model and also with those measured by the crosshead-arresting test to investigate the applicability of the KM model for the $\sigma-\varepsilon$ relations at the very low strain rates.

\section{Experimental Procedures}

Commercially available austenitic $25 \mathrm{Cr}-19 \mathrm{Ni}$ steel $(24.93 \mathrm{Cr}, 19.01 \mathrm{Ni}, 1.08 \mathrm{Mn}, 0.72 \mathrm{Si}, 0.04 \mathrm{C}, 0.024 \mathrm{P}$ in mass $\%$ ) plates were used in the as-received condition, i.e., as hot-rolled plates. ${ }^{4)}$ Round bar specimens with a gage diameter of $6 \mathrm{~mm}$ and a gage length of $30 \mathrm{~mm}$ were prepared. Figure 1 presents a nominal stress-nominal strain curve for the $25 \mathrm{Cr}-19 \mathrm{Ni}$ steel obtained by the tensile test with an ini- 


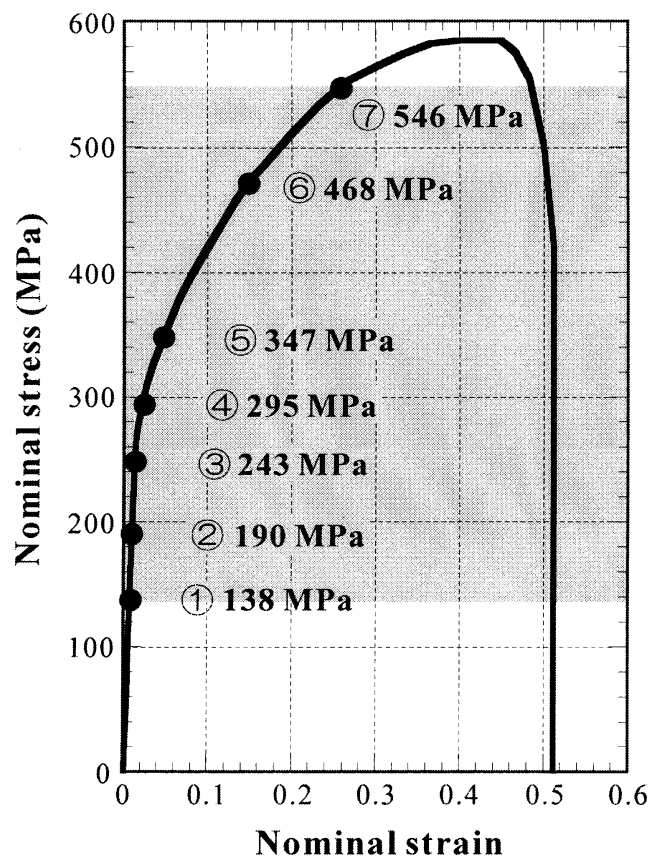

Fig. 1. Nominal stress-strain curve for the $25 \mathrm{Cr}-19 \mathrm{Ni}$ steel with an initial strain rate of $3.3 \times 10^{-4} \mathrm{~s}^{-1}$ at $296 \mathrm{~K}$, where the creep loads are indicated.

tial strain rate of $3.3 \times 10^{-4} \mathrm{~s}^{-1}$ at $296 \mathrm{~K}$. We chose the applied loads for the creep test, based on this curve. The creep test under the constant applied load was conducted at room temperature set at $293 \pm 2 \mathrm{~K}$ with uniaxial creep testing machines. ${ }^{9-11)}$ Several specimens that were crept were subjected to the tensile test with an initial strain rate of $3.3 \times$ $10^{-4} \mathrm{~s}^{-1}$ at $296 \mathrm{~K}$. The dislocation structure of the deformed specimens was observed by transmission electron microscopy (TEM). TEM disc samples were taken from the crept specimens in such a way that the normal plane of the TEM disc was perpendicular to the load direction.

\section{Computation Procedure for FLow Stress during Creep}

The outline of the Kocks-Mecking (KM) model ${ }^{1)}$ and the parameters determined in the previous report ${ }^{4)}$ are described briefly here. In the KM model, flow stress is described as a function of test temperature $(T)$, strain rate $(\dot{\varepsilon})$ and $\varepsilon$ as follows,

$$
\frac{\sigma}{\mu}=\frac{\hat{\sigma}_{\mathrm{a}}}{\mu}+s_{\mathrm{I}}(\dot{\varepsilon}, T) \frac{\hat{\sigma}_{\mathrm{I}}}{\mu_{0}}+s_{\mathrm{D}}(\dot{\varepsilon}, T) \frac{\hat{\sigma}_{\mathrm{D}}}{\mu_{0}}
$$

where $\mu$ is the temperature-dependent shear modulus ${ }^{12)}$ and $\mu_{0}$ the shear modulus at $0 \mathrm{~K}$. The first term of the right hand side, $\hat{\sigma}_{a}$, is the athermal stress, which is expressed as a function of the strain for the present steel.

$$
\hat{\sigma}_{\mathrm{a}}=150+1300 \varepsilon \mathrm{MPa}
$$

The second and third terms are the two different kinds of obstacles for the dislocation motion accompanying relevant thermal activation mechanisms. The second term refers to the Peierls potential barrier and solid solution hardening, where the mechanical threshold stress, $\hat{\sigma}_{\mathrm{I}}$, is lowered with thermal activation by a factor $s_{\mathrm{I}}(\dot{\varepsilon}, T)$. The third $\hat{\sigma}_{\mathrm{D}}$ term is the threshold stress to overcome the barrier caused by dislo-
Table 1. The parameters in the Kocks-Mecking model for the

\begin{tabular}{|c|c|}
\hline Parameter & Value \\
\hline$\hat{\sigma}_{a}$ & $150+1300 \varepsilon(\mathrm{MPa})$ \\
\hline$g_{0 I}$ & 0.17 \\
\hline$p_{I}$ & 0.5 \\
\hline$q_{I}$ & 1.5 \\
\hline$\hat{\sigma}_{I}$ & $680(\mathrm{MPa})$ \\
\hline$g_{O D}$ & 0.26 \\
\hline$p_{D}$ & 0.5 \\
\hline$q_{D}$ & 1.5 \\
\hline$\hat{\sigma}_{D s}$ & $840(\mathrm{MPa})$ \\
\hline$\Theta_{0}$ & $1600(\mathrm{MPa})$ \\
\hline$\dot{\varepsilon}_{0 I}$ & $10^{8}\left(\mathrm{~s}^{-1}\right)$ \\
\hline$\dot{\varepsilon}_{0 D}$ & $10^{8}\left(\mathrm{~s}^{-1}\right)$ \\
\hline
\end{tabular}
austenitic $25 \mathrm{Cr}-19 \mathrm{Ni}$ steel. ${ }^{4)}$

cation-dislocation interactions, which is also decreased by $s_{\mathrm{D}}(\dot{\varepsilon}, T)$. The following equations were adopted for $s_{\mathrm{I}}(\dot{\varepsilon}, T)$, $s_{\mathrm{D}}(\dot{\varepsilon}, T)$, and $\hat{\sigma}_{\mathrm{D}}$, respectively.

$$
\begin{aligned}
s_{\mathrm{I}}(\dot{\varepsilon}, T) & =\left[1-\left(\frac{k T}{g_{0 \mathrm{I}} \mu b^{3}} \ln \frac{\dot{\varepsilon}_{0 \mathrm{I}}}{\dot{\varepsilon}}\right)^{1 / q_{\mathrm{I}}}\right]^{1 / p_{\mathrm{I}}} \\
s_{\mathrm{D}}(\dot{\varepsilon}, T) & =\left[1-\left(\frac{k T}{g_{0 \mathrm{D}} \mu b^{3}} \ln \frac{\dot{\varepsilon}_{0 \mathrm{D}}}{\dot{\varepsilon}}\right)^{1 / q_{\mathrm{D}}}\right]^{1 / p_{\mathrm{D}}} \\
\hat{\sigma}_{\mathrm{D}} & =\hat{\sigma}_{\mathrm{Ds}}\left[1-\exp \left(\frac{-\Theta_{0} \varepsilon}{\hat{\sigma}_{\mathrm{Ds}}}\right)\right] \ldots \ldots \ldots
\end{aligned}
$$

Here, $g_{0}, \dot{\varepsilon}_{0}, q$ and $p$ are constants and their suffixes I and D refer to yielding and work hardening, respectively, $\Theta_{0}$ is the stage II work-hardening rate, and $\hat{\sigma}_{\mathrm{Ds}}$ the saturation stress of $\hat{\sigma}_{\mathrm{D}}$ at an arbitrary temperature and strain rate. $\hat{\sigma}_{\mathrm{D}}$ is increased during deformation with an increase in the dislocation density that generally depends on temperature and strain rate because of the occurrence of dynamic recovery. However, we expressed $\hat{\sigma}_{\mathrm{D}}$ for the present steel only as a function of strain neglecting the influence of dynamic recovery and determined the parameters as shown in Table 1. ${ }^{4)}$ These equations and parameters were used for the calculation of creep deformation.

\section{Results and Discussions}

Figure 2 shows the nominal strain versus log time curves obtained by the creep test at room temperature. The applied 


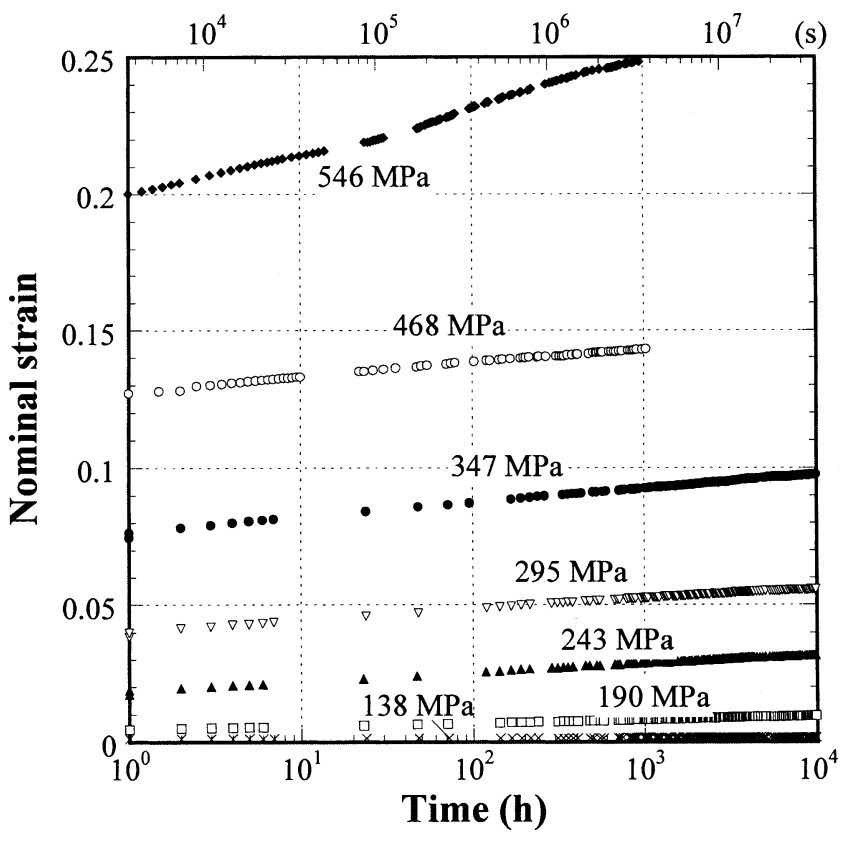

Fig. 2. Nominal strain $v s$. log time plots at room temperature.

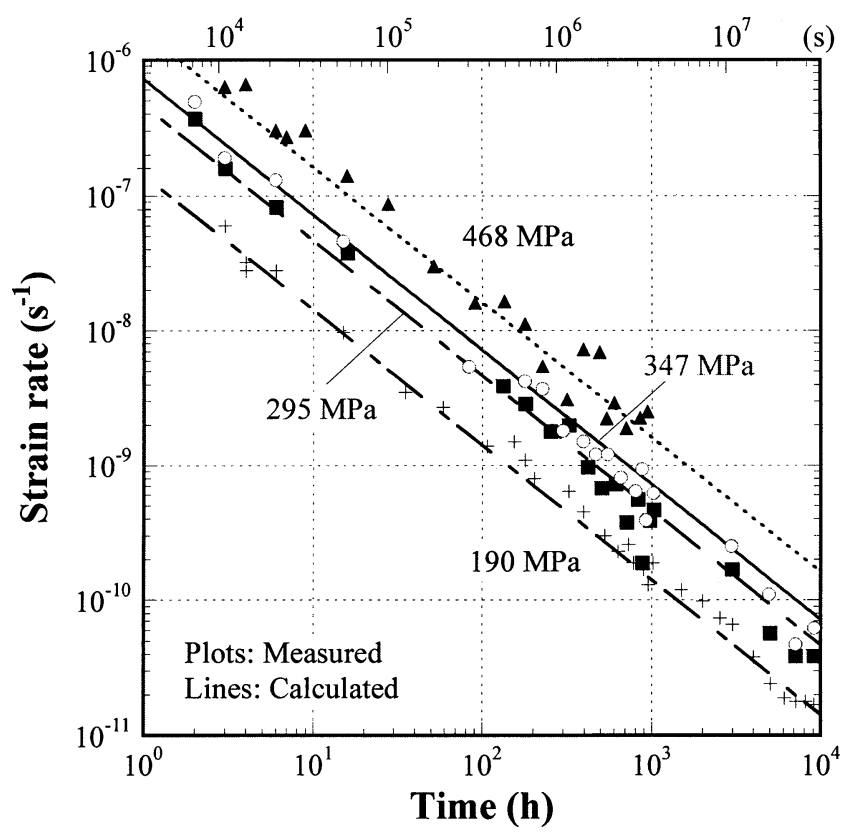

Fig. 3. Log strain rate $v s$. log time plots at the applied stresses of $190,295,347$, and $468 \mathrm{MPa}$.

stresses are shown in the figure. Figure 3 represents the strain rate $(\dot{\varepsilon})$ versus log time plots at the applied stresses of $190,295,347$, and $468 \mathrm{MPa}$. Strain rate decreases with an increase in holding time. The slopes of the strain rate in Fig. 3 are -1 at all the applied stresses, and the strain rate at $3.6 \mathrm{ks}(1 \mathrm{~h})$ depends on the applied stress. Based on those experimental results, the strain rate can be described as a function of time $(t)$ and the applied stress $\left(\sigma_{0}\right)$,

$$
\log \dot{\varepsilon}=-\log t+\log 10^{-13}+2.7 \log \sigma_{0}
$$

The lines in Fig. 3 show the changes in the strain rate calculated by using Eq. (6). The calculated strain rates show good agreement with the measured ones. However, the nominal strain-time curve of the applied stress for $546 \mathrm{MPa}$ was different from other applied stresses and the strain al-

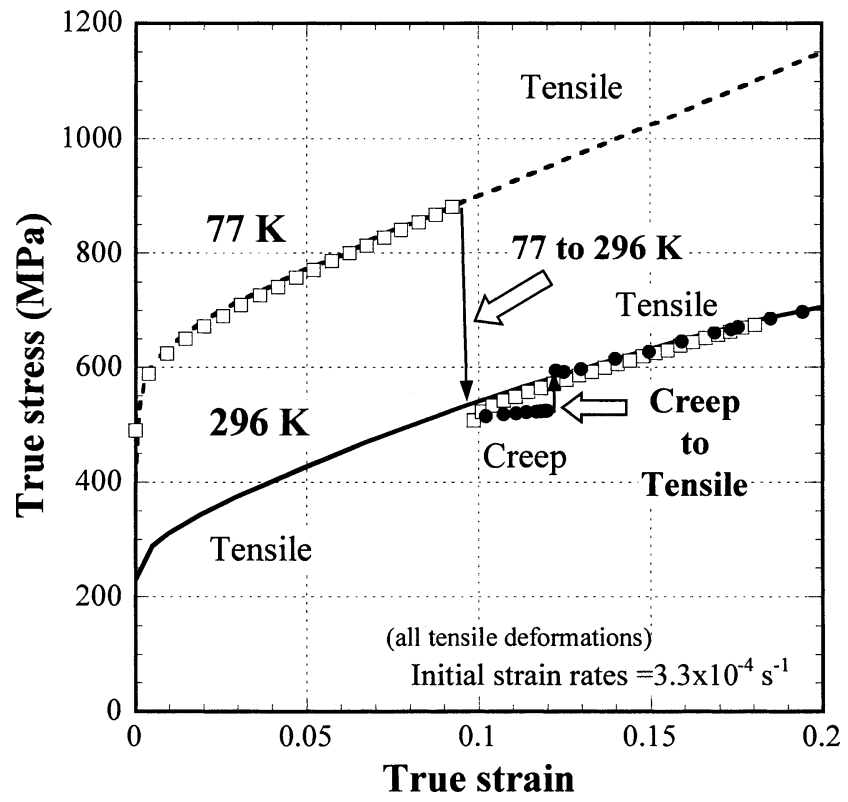

Fig. 4. Comparison of the $\sigma-\varepsilon$ relations obtained by the deformation test combining the creep test with the tensile test (O), the conventional tensile test (lines), and the temperature change test $(\square)$ at 77 and $296 \mathrm{~K}$.

ready exceeded 0.2 at the initial stage. Therefore, we will not discuss the $\sigma-\varepsilon$ relation of $546 \mathrm{MPa}$, near the ultimate tensile strength, in the following analysis.

In the previous paper, ${ }^{4)}$ when the temperature was changed from 77 to $296 \mathrm{~K}$ during tensile testing or the strain rate was changed from $10^{-4} \mathrm{~s}^{-1}$ to $10^{-9} \mathrm{~s}^{-1}$ and then back to $10^{-4} \mathrm{~s}^{-1}$, the flow stress exhibited little difference from that obtained at $296 \mathrm{~K}$ with $10^{-4} \mathrm{~s}^{-1}$ below a tensile strain of 0.2 . We conducted the creep deformation at the applied stress of $468 \mathrm{MPa}$ for $3.6 \mathrm{Ms}(1000 \mathrm{~h})$ prior to the tensile deformation with an initial strain rate of $3.3 \times 10^{-4} \mathrm{~s}^{-1}$ at $296 \mathrm{~K}$ to confirm the independence of the $\sigma-\varepsilon$ relations on the deformation history effect in the present alloy. Figure 4 shows these $\sigma-\varepsilon$ relations by closed circles. All the $\sigma-\varepsilon$ relations in the tensile deformation after three different deformation histories show good agreement and indicate that the $\sigma-\varepsilon$ relations at the same strain rate are almost identical when the specimen was deformed by either the tensile test or the creep test. Figure 5(a) shows the dislocation structure obtained from the specimen subjected to a tensile strain of 0.1 by the creep test with $347 \mathrm{MPa}$; the test was stopped at $36 \mathrm{Ms}(10000 \mathrm{~h})$. Figure 5(b) shows the dislocation structure obtained from the specimen subjected to 0.2 by the tensile test at $296 \mathrm{~K}$. Both microstructures consist of a high density of planar dislocations with an undeveloped dislocation cell and the absence of twinning. It is difficult to distinguish the difference in these dislocation structures that evolved either during the creep or tensile deformation.

Next, we investigate $\sigma-\varepsilon$ relations with very low stain rates obtained by different deformation modes and calculated by the KM model. Figure 6(a) shows the $\sigma-\varepsilon$ relations between $10^{-8}$ and $10^{-10} \mathrm{~s}^{-1}$ obtained by the room temperature creep test, those calculated by the KM model, and the $\sigma-\varepsilon$ relation of $10^{-9} \mathrm{~s}^{-1}$ measured by the crosshead-arresting test. ${ }^{4)}$ Figure $6(\mathrm{~b})$ shows a schematic illustration, which 

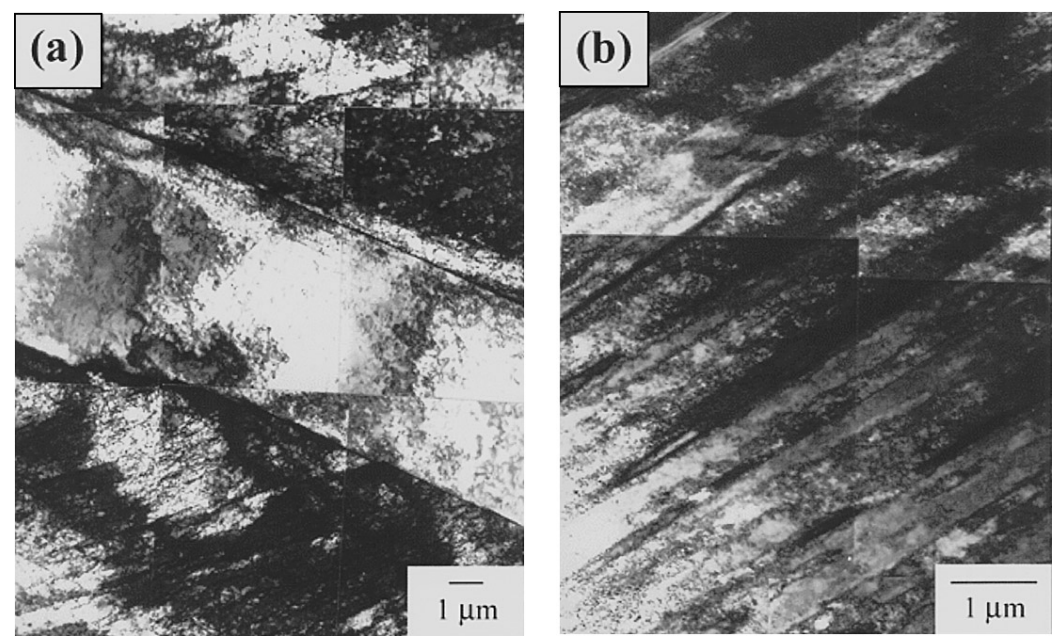

Fig. 5. TEM micrographs after deformation: deformed $10 \%$ by the creep test at $293 \mathrm{~K}$ (a) and deformed $20 \%$ by the tensile test at $296 \mathrm{~K}$ (b).
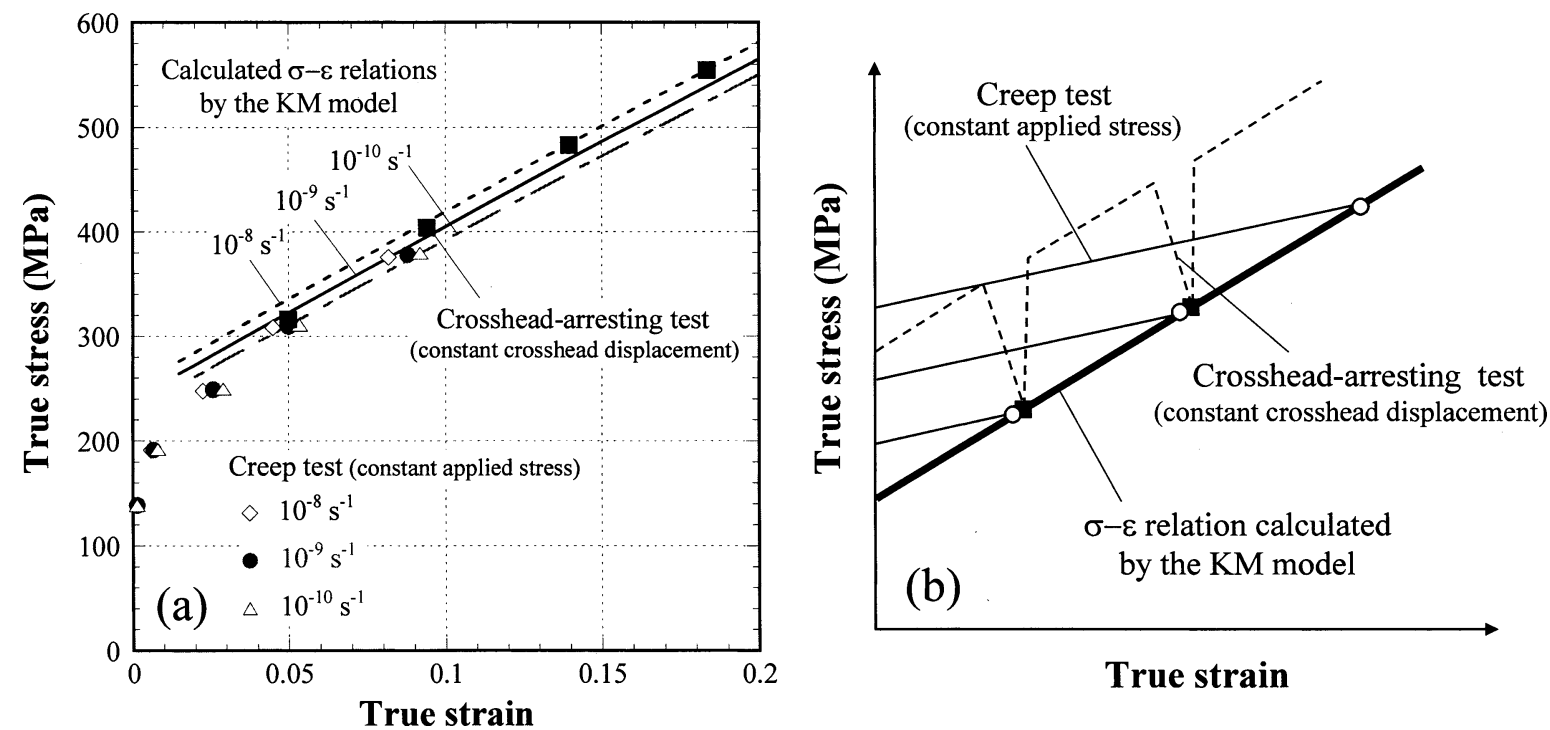

Fig. 6. (a) Comparison among the $\sigma-\varepsilon$ relations at very low strain rates between $10^{-8}$ and $10^{-10} \mathrm{~s}^{-1}$ obtained by the creep test, those calculated by the Kocks-Mecking model, and that measured by the crosshead-arresting test at $296 \mathrm{~K}^{4)}$ and (b) a schematic illustration to reach $\sigma-\varepsilon$ relations at the very low strain rates between the creep test and the crosshead-arresting test.

represents the difference in deformation history to obtain the $\sigma-\varepsilon$ relations at the very low strain rates between the creep test and the crosshead-arresting test. At first, we can observe that $\sigma$ and $\varepsilon$ with the same strain rate obtained by the room temperature creep tests have $\sigma-\varepsilon$ curves that are similar to those measured by the tensile tests. Secondly, when the $\sigma-\varepsilon$ relations obtained by the creep test are compared with those measured by the crosshead-arresting test and those calculated by the KM model, the three sets of data show good agreements at true strains below 0.2 . Hence, the $\sigma-\varepsilon$ relations with very low strain rates for the $25 \mathrm{Cr}-19 \mathrm{Ni}$ steel are almost independent of the deformation manner below a tensile strain of 0.2 and the KM model can apply to the $\sigma-\varepsilon$ relations at the very low strain rates.

\section{Conclusions}

We investigated true stress $(\sigma)$-true strain $(\varepsilon)$ relations with very low strain rates obtained by the creep test under a constant applied stress for an austenitic $25 \mathrm{Cr}-19 \mathrm{Ni}$ steel at room temperature. The influence of deformation history combined with creep and tensile tests on the $\sigma-\varepsilon$ relation was negligible below a tensile strain of 0.2 , suggesting that the microstructure evolution can be described as a function of the strain only. The $\sigma-\varepsilon$ relations with strain rates between $10^{-8}$ and $10^{-10} \mathrm{~s}^{-1}$ obtained by the creep test showed good agreement with the calculated $\sigma-\varepsilon$ relations by the KM model and the measured ones by the crosshead-arresting test. This means that the KM model is applicable to the $\sigma-\varepsilon$ relations at very low strain rates because the $\sigma-\varepsilon$ relations for the present steel are independent of the deformation history below a true strain of 0.2 .

\section{Acknowledgments}

The authors are grateful to Drs. F. Abe, K. Kubo, and K. Kimura of National Institute for Materials Science for their help and advice in the room temperature creep test. Gratitude is also extended to Dr. J-H. Park and Mr. M. 
Kanda, graduate students of Ibaraki University, for their help in the room temperature creep test.

\section{REFERENCES}

1) P. S. Follansbee and U. F. Kocks: Acta Metall., 36 (1988), 81.

2) N. Tsuchida, H. Moriya, Y. Tomota, O. Umezawa and K. Nagai: ISIJ Int., 40 (2000), 84

3) H. Moriya, K. Nagai, Y. Kawabe and A. Okada: ISIJ Int., 37 (1997), 1016.

4) N. Tsuchida, Y. Tomota, H. Moriya, O. Umezawa and K. Nagai: Acta Mater, 49 (2001), 3029.

5) J-H. Park, Y. Tomota, S. Takagi, S. Ishikawa and T. Shimizu: Tetsuto-Hagané, 87 (2001), 657.
6) N. Tsuchida, Y. Tomota and K. Nagai: unpublished data.

7) C. C. Bampton, I. P. Jones and M. H. Loretto: Acta Metall., 26 (1978), 39.

8) Handbook of Stainless Steels, ed. by D. Peckner and I. M. Bernstein McGraw-Hill Inc., New York, (1977), 4.

9) ASTM E139-70. ASTM, E150-64.

10) ASM Handbook Vol. 8, ASM International, Ohio, (2000), 369.

11) TESTING PLAN AND TESTING PROCEDURES FOR NRIM CREEP DATA SHEETS PROJECT. NRIM Material Strength Data Sheet Technical Document No. 10, NRIM, Tokyo, (1996). (in Japanese.)

12) H. J. Frost and M. F. Ashby: Deformation Mechanism Maps, Pergamon Press, New York, (1982), 20. 